\title{
What Can We Do About Climate Change?
}

\author{
By Roger R. Revelle*
}

\begin{abstract}
$T_{1}$
HERE IS a good, but by no means certain, chance that the world's average climate will become significantly warmer during the next century, because of the increasing atmospheric concentrations of infrared-absorbing and re-radiating, so-called "greenhouse" gases. These comprise compounds with three or more atoms per molecule. They included carbon dioxide, methane, nitrous oxide, chlorofluorocarbons, tropospheric ozone, and several others present in trace concentrations (water vapor is also a greenhouse gas).

Research and observations over the next 10 to 20 years should give us a much better idea of the likely magnitude of atmospheric and oceanic warming during the twenty-first century. In the meantime we should think of ways to mitigate, adapt to, and better understand future global change and its effects on our society and our environment.

There are at least six kinds of actions that could be taken to mitigate and delay climatic warming:
\end{abstract}

1. Changing the mix of fossil fuels to use more methane and less oil and coal;

2. Energy conservation, i.e., increasing energy efficiency, the benefits obtained per unit of energy used;

3. Substitution of non-fossil energy sources for coal, oil and natural gas;

4. Sequestration of organic carbon in the deep sea by stimulating spring phytoplankton production in high-latitude oceans;

5. Sequestration of carbon in trees and other long-lived land plants;

6 . Increasing the earth's albedo (the percentage of sunlight reflected from the surface and the atmosphere to outer space).

Combustion of methane produces about twice as much energy per gram of carbon dioxide as does the combustion of coal, and about fifty percent more than combustion of oil. It is also a "clean," relatively non-polluting fuel. We need to expand greatly and to conserve the world reserves of methane, particularly those of the United States. This may very well involve greater understanding of its modes of formation and accumulation.

The possibilities of energy conservation have recently been examined by Starr and Searl in a paper prepared for the Electric Power Research Institute: "Global Electricity Futures: Demand and Supply Alternatives." They concluded that "with full conservation" the annual growth rates of energy use per capita could be reduced for the world popu-

* R.R. Revelle, Scripps Institution of Oceanography, University of California at San Diego, LaJolla, CA 92093. USA. Deceased. lation as a whole (and also for the populations of developed countries) from $1.1 \%$ per year to $0.35 \%$ per year, so that total world energy use in 2060 would be only about two and a half times that in 1986, even though the population will increase from about 5 to 9.7 billion people, and per capita energy use for the less developed countries will more than double, from 20 million BTUs per year to 45 million. Per capita electricity use in the poor countries will go from five hundred kilowatt hours to nearly twenty-four hundred kilowatt hours per year, and in the developed countries from less than seven thousand kilowatt hours per year to 16.5 thousand.

Starr and Searl have estimated the economic possibilities for substitution of nonfossil energy sources. They compute that in the year 2060, 75 quads (quadrillion BTUs) of direct solar energy obtained with photovoltaic converters could be used, [in addition to] 125 quads of "biomass" energy from trees, agricultural wastes and crops grown specifically for energy production. If 200 quads of nuclear energy were available, it would still be necessary to obtain 400 quads from fossil fuels and hydropower. (The latter is a fairly small fraction of present energy sources). The relatively small amount of solar power that could be utilized results from the diurnal variation in sunlight and from the fact that in many areas the sun is masked by clouds for days on end. Starr and Searl claim that storage of solar energy, though possible, is too expensive. They give no reason, however, for limiting the quantity of nuclear energy that could be used 70 years from now. With their assumed use of fossil fuels, the atmospheric burden of carbon would increase by about 250 gigatons compared with the present amount of 700 gigatons.

One possibility for "fuel" substitution not considered by Starr and Searl is ocean thermal energy conversion (OTEC) utilized to produce hydrogen by electrolysis of water. The hydrogen could be transferred to the shore in suitable containers from floating OTEC power plants that would "graze" tropical waters. The hydrogen could be used in a variety of ways as completely "clean" fuel.

John Martin, of the Moss Landing Marine Laboratories, has pointed out that the phytoplankton production in the waters surrounding Antarctica is very low in spite of the abundance of phosphorus and nitrogen in these waters. He believes that this lack of biological production is due to the deficiency of iron (required to make chlorophyll). If a suitable spreading device could be devised, the scattering of a few hundred thousand tons of finely divided iron particles over the ten million or so square kilometers of the Antarctic Ocean should result, Martin suggests. in production of one or two billion tons of organic carbon in phytoplankton. Presumably a large part of this biomass would settle to the sea floor, thereby sequestering the carbon.

President Bush has proposed planting a billion trees a year for the next ten years in the United States. These plantings might cover 25 million acres with a density of about four hundred trees per acre. Over twenty years, if the trees had sufficient water and were of suitably fast-growing varieties, each tree would accumulate perhaps one ton of organic carbon. The total rate of carbon accumulation would be about half a billion tons per year, quite a large fraction of the total anthropogenic carbon emissions to the air from the United States.

Another possibility for utilizing trees to sequester organic carbon might be a natural consequence of climate warming, with the corresponding spread of boreal forests toward the north in Canada, Scandinavia and Siberia. In a recent article, I have shown that the area of boreal forests might increase by about 500 million hectares over the next fifty years, and that the growth rate in both old and new boreal forests might rise to 2.16 metric tons of carbon per hectare per year, or 2.7 billion tons ("Thoughts on Abatement and Adaptation" in Greenhouse Warming: Abatement and Adaptation, edited by Norman J. Rosenberg, William E. Easterling III, Pierre R. Crosson and Joel Darmstadter; published by Resources for the Future, 1989).

Wallace Broecker has suggested still a sixth mechanism for mitigation of climatic change. He points out that sulfur dioxide particles ejected by volcanoes persist in suspension in the upper atmosphere for several years, with a significant increase in earth's albedo. He suggests that a similar veil of tiny sulfuric acid particles could be dispersed artificially in the upper stratosphere by aircraft.

Adaptation to climatic warming and to probable changes in water supplies should be fairly straightforward by suitable genetic modification of important crop plants such as maize and wheat. This has been pointed out by Paul Waggoner in his chapter on "Agriculture and a Climate Changed by More Carbon Dioxide" in the National Research Council publication, Changing Climate (pp. $383-418,1983$ ). It may be more difficult to help forest trees and other ecological components to adapt, because the expected climate change will happen fifty to one hundred times more rapidly than the changes at the end of the last ice age. Considerable research may be necessary to gain an understanding of what needs to be done.

Research is also necessary to gain greater understanding of the role of the oceans in the changing distribution of carbon dioxide and 
other greenhouse gases and in changes of oceanic and atmospheric climate. For example, the steady-state general circulation models indicate that the extent of warming will be much greater at high latitudes than in the southern parts of the United States. But the transient conditions should be different because a longer time will be required to warm the high-latitude oceans, with their deep vertical circulation, than the tropical and temperate waters that are much more strongly stratified. Experiments, such as that proposed by Walter Munk, using round-the-world acoustic signals from Heard Island in the Australian Antarctic to attempt to measure temperature change in the interior of the oceans should be very useful.

Recently, Taro Takahashi and Inez Fung have convinced themselves that fossil-fuel $\mathrm{CO}_{2}$ emitted to the atmosphere in recent years is being taken up by the land biosphere and not by the oceans. This almost revolutionary idea needs to be checked by careful measurements of inorganic and organic $\mathrm{CO}_{2}$ dissolved in the oceans and by estimates of the influx and eflux of $\mathrm{CO}_{2}$ into and out of different areas in the oceans. We know that near the equator and in other areas of upwelling, there is a large flow of $\mathrm{CO}_{2}$ from the ocean to the air. While in high and middle latitudes, at least during certain seasons, the reverse is true. This is a question of more than academic interest because, as the atmospheric content increases, conditions at the ocean-atmosphere interface are bound to change in unknown ways.

\title{
R/V ThOMAS G. THOMPSON (AGOR-23)
}

\author{
The Newest Addition to the UNOLS FleEt
}

$\mathrm{O}$ N JULY 8th, 1991, the School of Oceanography at the University of Washington took delivery of the $\mathrm{R} / \mathrm{V}$ Thomas G. Thompson (AGOR-23). Construction of the R/V Thomas $G$. Thompson was funded by the Navy for support of basic oceanographic research by the UNOLS (University-National Oceanographic Laboratory System) community. The ship will be operated by the University of Washington on behalf of the Northwest Consortium for Ocean Research (NORCOR, comprised of the University of Washington, University of Alaska, and Oregon State Uni- versity) under a charter party agreement with the Office of Naval Research (ONR). The R/V Thomas G. Thompson is a general-purpose oceanographic research ship that has unique capabilities for positioning, support of a large scientific party, and endurance.

After delivery of the new ship at the Halter Marine, Inc., shipyard in Moss Point, Mississippi, a 30-day shakedown/ transit cruise to San Diego was completed. Two ONR-funded research cruises to the Fieberling Guyot are the ship's first research assignments.

Operations in 1992 are mainly in support of the Joint Global Ocean Flux Studies (JGOFS) program in the equatorial Pacific, with time set aside in the summer for shipyard availability to correct construction warranty deficiencies and accomplish retrofit items approved by the Navy.

Information concerning the ship and ship time requests may be obtained by contacting Russell McDuff, Associate Director for Research Operations, School of Oceanography, WB-10, University of Washington, Seattle, WA 98195 .

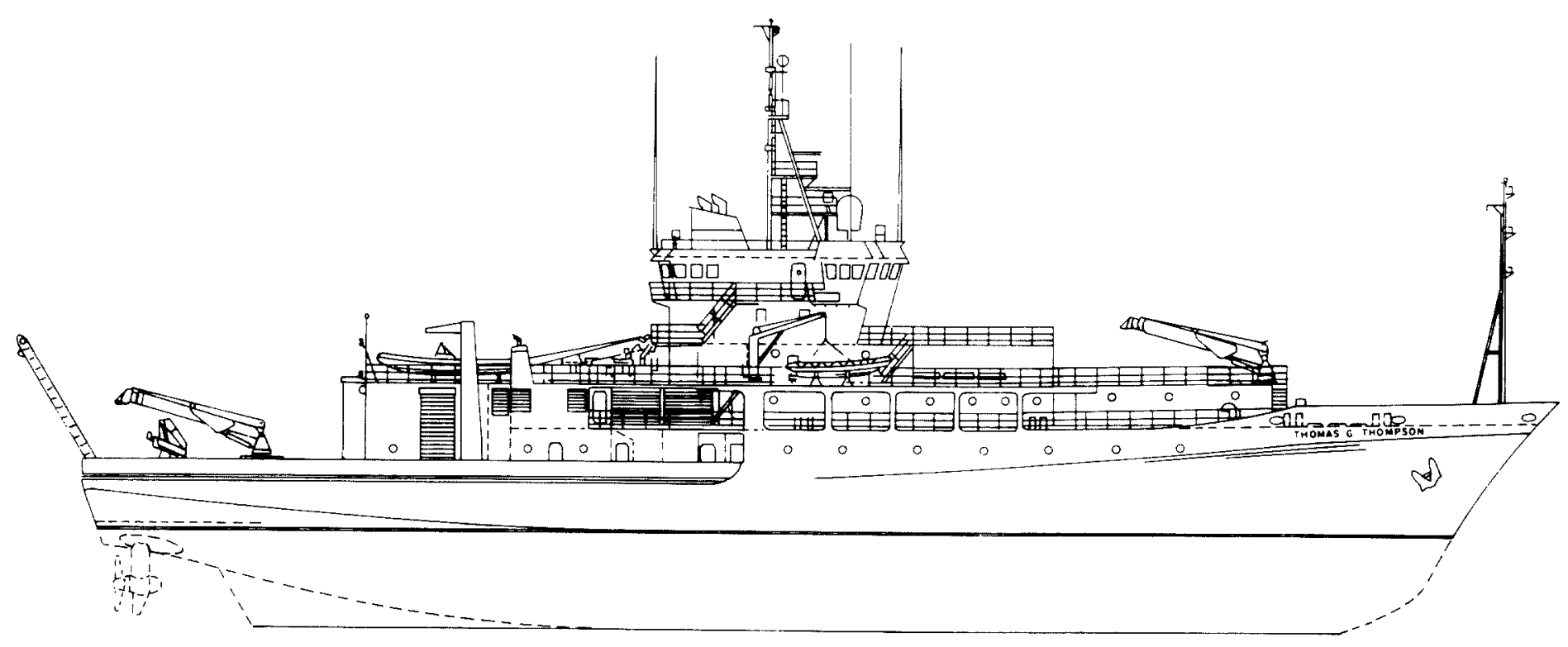

